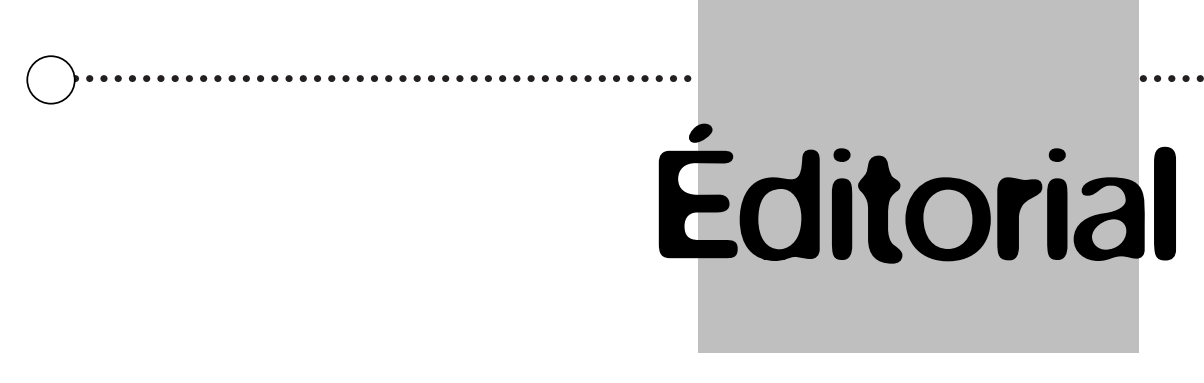

\title{
... nec mergitur ! PP va belle erre...
}

\author{
Dr Pascal RICHARD \\ Rédacteur en Chef sortant
}

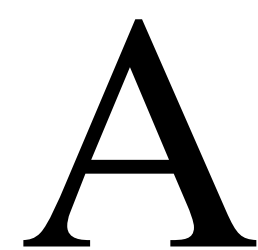

vec ce numéro de Perspectives Psy se termine le mandat que le GEPPSS m'avait confié fin 1998. Assumer pendant huit ans les fonctions de rédacteur en chef d'une telle revue fut, vous en doutez, une tâche à la fois passionnante et exigeante ; une tâche que je n'aurais jamais pu espérer mener à bien sans l'ensemble du Comité de Rédaction et des membres correspondants, sans oublier nos illustres parrains du Comité Scientifique. Je les remercie tous très chaleureusement.

Pendant huit ans, j'ai eu le sentiment grisant de tenir un poste de vigie, d'où je pouvais observer, tant à travers les textes et dossiers proposés pour publication que lors des réunions du Comité de Rédaction, à quels points restaient vifs et stimulants les débats qui animent les champs des disciplines dont la revue se fait la tribune : «Psychiatrie, Psychologie et Sciences Sociales ».

Parfois, la houle était telle que je ne pouvais rester, contemplatif, dans la mâture. Il me fallait alors descendre à la passerelle pour veiller sur la barre, pour rappeler le cap et trancher en faveur de telle ou telle stratégie éditoriale. Tenir les ciseaux du censeur ou faire acte d'autorité m'a toujours rebuté, mais mon rôle était aussi de devoir assumer des décisions difficiles. Heureusement, les talents de diplomates de quelques un des fidèles du Comité de Rédaction, ainsi que la qualité rédactionnelle des textes publiés, ont toujours permis que PP garde sa place au sein des publications psychiatriques francophones.

Déjà, dans l'éditorial du $1^{\text {er }}$ numéro de PP en 1963, Claude Le Guen affirmait ce qui reste le mot d'ordre pour notre Rédaction : « [...] nous voulons que cette revue contribue à susciter des vocations psychiatriques et à former des psychiatres. [...] C'est dire que nous nous bat- trons toujours pour que notre discipline soit connue, respectée et sauvegardée ».

$\mathrm{Ce}$ combat, qui concerne également les cliniciens intervenant dans les domaines de la psychologie et des sciences sociales, impose que notre revue se serve des armes de notre temps pour que l'ancrage clinique de nos disciplines ne soit pas oublié ou dénié. La clinique à laquelle nous nous référons est celle qui garde toute leur place aux notions de sujet et de fait psychique. Les armes qu'il nous faut apprendre à utiliser ont pour nom rigueur rédactionnelle, respect des délais, indexation dans les bases de données internationales... Beaucoup reste à accomplir sur ces points, la réalisation du présent numéro m'en ayant encore, hélas, apporté la preuve.

Pendant ces huit ans, j'ai aussi passé beaucoup de temps (et $\mathrm{j}$ 'ai pris beaucoup de plaisir) à visiter les cales, à veiller à ce que les machines soient bien huilées. J'y ai beaucoup appris sur ce qui fait qu'une revue comme PP puisse exister, et j'ai souvent regretté que les auteurs soient si peu conscients de tout le travail éditorial qui permet, concrètement, la publication, la diffusion et le partage des connaissances scientifiques. Je tiens ici à remercier profondément Martine Krief et François Flori, des Éditions EDK, pour leur indéfectible soutien et pour leur vigilante efficacité ; c'est aussi grâce à eux que, même par gros temps, la revue continue d'être publiée.

Vous l'aurez compris, je me figure PP comme un beau navire dont j'ai demandé à débarquer après une mission qui m'a beaucoup mobilisé. Grâce à une année de fructueuse collaboration, la relève est maintenant assurée, chacun est à sa place et la revue peut continuer sur son erre. À la nouvelle équipe et au Dr Jean-Marc Guilé, notre nouveau rédacteur en chef, je souhaite «Bon vent et bonne mer ! ». 